\title{
Pooling Restaurant Reservations to Increase Service Efficiency
}

\author{
Gary M. Thompson* \\ and \\ Robert J. Kwortnik, Jr. \\ Published in the Journal of Service Research (2008), 10 (May), pp, 335-46. \\ *Gary M. Thompson is Professor of Operations Management, School of Hotel Administration, \\ Cornell University, 352 Statler Hall, Ithaca NY 14850, phone: 607-255-8214, fax: 607-254- \\ 8839, email: gmt1@ cornell.edu. Robert J. Kwortnik, Jr. is Assistant Professor of Services \\ Marketing, School of Hotel Administration, Cornell University, 545 Statler Hall, Ithaca NY \\ 14850, phone: 607-254-6543, fax: 607-255-1355, email: rjk34@ cornell.edu.
}

Key words: service process, revenue management, restaurant reservations, simulation, customer experience, resource pooling 


\title{
Pooling Restaurant Reservations to Increase Service Efficiency
}

\author{
ABSTRACT \\ This paper examines whether restaurant reservations should be locked to specific tables at the \\ time the reservation is made, or whether the reservations should be pooled and assigned to tables \\ in real-time. In two motivating studies, we find that there is a lack of consensus in the restaurant \\ industry on handling reservations. Contrary to what might be expected based on research that \\ shows the benefits of resource pooling in other contexts, a survey of 425 restaurants indicated \\ that over $80 \%$ lock reservations to tables. In two simulation studies, we determine that pooling \\ reservations enables a 15-minute reduction in table turn times more than $15 \%$ of the time, which \\ consequently increases service efficiency and enables a restaurant to serve more customers \\ during peak periods. Pooling had the most consistent advantage with higher customer service \\ levels, with larger restaurants, with customers who arrive late, and with larger variation in \\ customer arrival time.
}




\section{INTRODUCTION}

Restaurants and other capacity-constrained services, such as spas, hotels, golf courses, hair salons, and dental offices face variable demand that makes it difficult to optimize perishable inventory (Kimes and Chase 1998). One way service firms try to manage this uncertainty is with reservations, which represent a normative and often explicit contract describing the rights and obligations of customers and service providers (Wilson 2007). Reservations can take a variety of forms, from unconditional verbal agreements, such as a telephone request to reserve a restaurant table for a specific party size on a particular day, to conditional contracts that impose terms and penalties on the customer for cancellation or reneging (i.e., being a "no-show"). Permitting customers to "lock in" service with a reservation reduces uncertainty for both parties to the exchange, though this benefit can reduce a service providers' revenue when customers fail to show or arrive late, and when customers without reservations are turned away. However, these issues have received little scholarly attention in the services-management literature.

The aim of this research is to examine how assigning restaurant reservations to tables affects operational efficiencies. The motivation for this research came from an experience of the authors when they were on a sea cruise together with their families on a cruise line that pioneered the concept of unscheduled cruise dining - a model that has been imitated in various forms by several of the world's largest cruise brands. Located throughout the ship were flatscreen monitors displaying the occupancy status of onboard restaurants. The monitors often showed restaurants as being full, but in-person inspection of the restaurants typically revealed many empty tables. When queried about the discrepancy, the ship's personnel, attributed some of the cause to the reservation-management system, where specific tables were blocked out for two hours for each reservation, even though most parties finished dining within 90 minutes. We believed there were two issues at work: the first was simply whether 120 minutes was too long to block-out tables, but the second was whether it made sense in terms of service-process design to lock reservations to specific tables.

Restaurants use reservations to smooth demand, to optimize capacity, and to minimize queues, which detract from the customer experience. Reservations are most often used in finedining restaurants that offer sit-down table service and food that usually is prepared from scratch for each order, or during peak periods in mid-scale restaurants that offer table service and a mix of already-prepared and made-to-order menu items. Since our focus in this paper in on restaurant reservations management, specifically how handling reservations can affect a restaurant's capacity and customer flow, our work applies mainly to fine-dining and mid-scale restaurants.

The main issue we examine is whether reservations should be locked to specific tables at the time the reservation is made, or whether reservations should be pooled and assigned to tables in real-time. We refer to these approaches as locking (or locked) and pooling (or pooled), respectively. Consider a restaurant with four tables (see Figure 1). In the locked approach, each reservation would be linked to a specific table, allowing up to four reservations for each seating. In the pooled case, the restaurant would still take only four reservations per seating, but a reservation would be matched to a table only when the customer party arrived at the restaurant. Locking requires that each reservation include a sufficient time buffer to deal with uncertainty in meal durations and arrival times. Pooling provides greater flexibility because, by delaying the allocation of reservations to tables until the moment a party arrives, the statistical variations in dining durations and arrival times can be pooled. This flexibility becomes more important under conditions such as increased variability in demand timing (e.g., early arrivals) or duration (e.g., long meals). However, as we report later, many restaurant managers perceive benefits to locking 
reservations to tables; therefore, empirical support is needed to verify if a pooled versus locked approach provides significant service efficiencies and under what conditions.

[Figure 1 here]

In a recent Journal of Service Research editorial, A. Parasuraman called for papers that fall outside the norm of empirical work and that are from disciplines other than marketing (Parasuraman 2007). We respond to this call by using a multi-method approach, including a survey of 425 restaurants and two simulation studies, and by focusing on an operations management issue in services. We make two main contributions to the services literature. First, we identify the means by which resource pooling - a concept that has been studied in other operations-management contexts — can be applied in services like restaurants. Second, we demonstrate the benefits of resource pooling and identify conditions that influence the effectiveness of pooling reservations as a method to improve service processes and the customer experience. We next review the literature and describe two motivating studies and two simulation studies designed to test our research hypotheses. We close with a discussion of findings and implications for services management.

\section{LITERATURE REVIEW}

Issues related to managing capacity in restaurants have begun to receive attention in the operations management literature. There are a variety of factors that potentially limit capacity in restaurants, including the back-of-house (e.g., the kitchen); the wait-staff; the number, size, and position of tables; and parking spaces. One tool restaurant managers can use to optimize capacity is table mix - the specific number of certain-size tables in a restaurant (c.f., Thompson 2002; Kimes and Thompson 2004, 2005). Researchers also have examined the effects of dining duration and its variability, information that we use in setting the factor levels in our simulation studies. For example, Kimes and Robson (2004) reported on how dining durations in a mid-scale restaurant vary based on where customers sit. Kimes and Thompson (2005) presented mean dining times by party size and day of week for a mid-scale restaurant. Finally, Bell and Pliner (2003) showed that dining durations increase with party sizes across several restaurant settings.

An important metric of restaurant performance is the table turn time, which is the amount of time from the initial seating of a party until the party departs and the table is prepped for the arrival of another party. Faster table turns increase service efficiency and enable a restaurant to serve more parties during peak dining periods. However, it is important to consider customers' perceptions to ensure that they do not feel rushed (Kimes, Wirtz, and Noone 2002).

There is a large literature on a problem similar to restaurant reservations-appointment scheduling, particularly with respect to health care (c.f., Cayirli and Veral 2003, Vanden Bosch and Dietz 2001). While appointment scheduling and restaurant reservations involve blocking out a resource in advance of a customer's arrival, they differ in one key aspect. In appointment scheduling there is typically a single resource of interest (e.g., a physician), whereas restaurants usually have many fungible tables. There is little research related to reservations management in restaurants. An exception is the work of Bertsimas and Shioda (2003), who proposed a two-step approach: in phase one, which is performed in advance, managers set the number of reservations to take, and in phase two, which is performed in real time, they decide whether to accept or reject each party (even parties with reservations may be turned away).

Pooling restaurant reservations has parallels in the general operations management literature. In a manufacturing setting this can be seen with research on parts commonality, which 
is the degree to which manufactured goods share common (i.e., pooled) parts. Increasing the commonality of component parts allows a reduction in aggregate levels of safety stock, while maintaining the customer service level (Collier 1982) and a reduction in the lead time between order placement and delivery (Sheu and Walker 1997). In service settings, benefits have been observed for pooling both employees and equipment. Thompson (1999) reported on the cost reductions possible when using a pool of cross-trained employees, compared to staffing tasks independently with single-skilled employees. Pasin, Jobin, and Cordeau (2002) found that equipment pooling in local health care facilities reduces costs while maintaining service levels. The diversity of environments in which resource pooling yielded benefits leads to the main proposition of our study, that pooling restaurant reservations will enable better matching of service supply and demand, with consequent positive effects on a firm's service efficiency and revenues.

\section{MOTIVATING STUDIES: RESERVATIONS MANAGEMENT IN PRACTICE}

To gauge whether there was agreement in the restaurant industry about how to handle reservations, we conducted two surveys using different contact methods and samples. In our first survey, we contacted vendors of restaurant table management systems to inquire about how their systems handle reservations. We identified vendors using a Google search on April 20, 2007 for "restaurant reservation systems," later supplemented with the OpenTable vendor, which is used in a large number of restaurants. Table 1 shows that three of the seven systems for which we received information lock reservations to tables, one system pools reservations, and three systems allow the user to choose whether to pool reservations or lock them to specific tables.

\section{[Table 1 here]}

For our second motivating study, we developed a 22-question online survey. Respondents were from a list of 2,500 individuals who had previously downloaded restaurant-related material from a hospitality research center. We recruited participants in waves of 1,000,1000, and 500 with an email invitation and offer of a prize drawing of $\$ 100$ gift certificates. After removing 820 names due to bad email addresses or because respondents were not currently or recently the owner or employee of a restaurant, we received 425 usable surveys for a response rate of $25.3 \%$. Of these respondents, 68 (16.0\%) do not use a reservation system to manage demand; therefore, the main sample is comprised of 357 restaurants. Eighty percent of respondents are restaurant managers or owners. More than half of the restaurants are independently owned, and one out of four is part of a chain. The sample features considerable variability in terms of restaurant size, with a range of 8 to 2,000 seats (mean 143 and median 120 seats). Table mix was also varied, with 2-, 4-, 6-, and 8-tops (in that order) the most common table types. Finally, and notably, $64.1 \%$ restaurants in the sample use a paper-based reservation system, $28.9 \%$ use a custom computerized system, and the rest (7\%) use Opentable.com or another commercial system.

To address the focal question of the prevalence of locking versus pooling, we asked, "Which of the following best describes the dining-reservations process used at your restaurant?" Most restaurants lock reservations: 151 restaurants $(42.3 \%)$ responded that "reservations are assigned to specific tables by party size when the reservation is made," and 140 restaurants $(39.2 \%)$ responded that "reservations are assigned to specific tables by party size at the 
beginning of the meal period." Only 51 restaurants (14.3\%) responded that "reservations are not assigned to specific tables until the party arrives at the restaurant."

To better understand why restaurants lock reservations, we asked respondents to select from a proposed list of benefits of the practice. As shown in Table 2, respondents report that locking simplifies reservations and table management; permits a better view of table availability; enables easier physical arrangement of the table mix before guests with reservations arrive; allows for accommodation of guests who request specific tables; and, reduces the possibility of reservations and seating errors. The latter point is important because we find that restaurants permit a variety of people to take reservations: owner or manager $(47.6 \%$ of restaurants sampled), host or hostess $(56.6 \%)$, servers or bartenders $(20.5 \%)$, or any employee $(34.7 \%)$, though restaurants primarily give responsibility for managing reservations and table assignments to the owner or manager ( $71.7 \%$ of restaurants sampled) or host or hostess $(68.9 \%)$.

\section{[Table 2 here]}

The finding that the majority of our sampled restaurants lock reservations to tables is significant, especially if this approach creates service inefficiencies depending upon demand uncertainty. Our data reveal, for example, that $43.7 \%$ of the restaurants have a fixed ratio of reservations to walk-in guests for the main dining period, with an average of only $23.9 \%$ of tables held open for walk-ins. However, respondents report that $10.7 \%$ of reservations are "noshows," and that restaurants wait an average of 28 minutes before classifying these reservations as no-shows. These results suggest that restaurants which use less flexible approaches to managing tables, such as a high ratio of reservations to walk-ins or locking reservations to tables, may experience under-utilized tables when customers are late or fail to show up at all.

We find that restaurants use various means to reduce the level of uncertainty in customer flow prior to the dining period. For example, $45.4 \%$ of sampled restaurants call customers within 48 hours of their reservation to confirm. Another $21.3 \%$ take a credit card number as part of the reservation, though only $5.6 \%$ impose a fee or deposit. Restaurants also use a variety of tactics to smooth demand during the dining period. For example, if a party with a reservation arrives and the table to which they were locked is occupied, $66.9 \%$ of restaurants will assign the party to the next available table that matches their party size. However, $12 \%$ of restaurants will ask the party to wait until their assigned table becomes available (10.9\% give customers a choice of waiting or taking the next available table). In addition, $25.5 \%$ of restaurants will advise the party that is already seated that there is a time limit for use of a table or that there is a party waiting, whereas $26.6 \%$ of restaurants will ask customers who have finished their meal to move to the bar or an overflow area. To avoid such intrusive actions, $46.2 \%$ of restaurants add slack time to their estimates of the typical table-turn time. Finally, to reduce the impact of no-shows, $26.3 \%$ of restaurants overbook an average of $10.4 \%$ beyond restaurant capacity.

The convergent findings from the motivating studies suggest that there is little consensus in the restaurant industry on how to handle reservations. Restaurants tradeoff the flexibility of a reservation-pooling system for the perceived benefits that locking reservations provides, in

\footnotetext{
${ }^{1}$ To ensure that the results for the locking-versus pooling question were not biased by the wording of the response items, the third wave of our email invitation (500 addresses, 361 usable addresses, 87 respondents) received a survey with more precise response-item wording: "reservations are assigned to specific tables by party size (e.g., Table \#10, a two-top) when the reservation is made," and "reservations are assigned to specific tables by party size (e.g., Table \#10, a two top) at the beginning of the meal period." Analysis of the response frequencies across reservationmanagement approaches revealed no significant differences between the samples based on wording of this question $\left(\chi^{2}(5 d f)=2.47, \mathrm{p}>.1\right)$; therefore, the samples were combined.
} 
particular, a simpler approach to managing reservations, assigning tables, arranging the table mix, and visualizing the entire system. However, locking reservations also requires adaptive process-management tactics to handle no-shows, waits, and customer flow. We also propose that locking reservations will produce service inefficiencies of varying magnitudes based on different demand and capacity conditions. The studies that follow are designed to test this proposition.

\section{SIMULATION STUDIES}

Simulation models have proven to be effective in evaluating alternate configurations of services (c.f., Pullman and Thompson 2003, Thompson and Verma 2003). Consequently, we use a simulation model of the flow of customer parties in a restaurant in relation to the reservation process. We next describe the hypotheses driving our simulation studies and explain the design, present the results, and discuss limitations of the studies.

\section{Hypotheses}

In restaurants, pooling reservations cannot work worse than locking reservations since the (pooled) reservation can always be assigned to the table it would have been assigned to had the reservation been locked. The only question, then, is whether the greater flexibility that pooling offers actually improves service efficiency through faster table turns. Given that earlier research has demonstrated the benefits of resource pooling in manufacturing and service settings (Collier 1982, Pasin et al. 2002, Sheu and Walker 1997, Thompson 1999), our primary hypothesis is:

Hypothesis 1: Pooling reservations will yield faster table turns than will locking reservations to tables.

In addition to our primary hypothesis, we have a number of secondary hypotheses related to the conditions under which we expect pooling to yield service efficiencies. For this study, we define customer service level to be the percentage of parties that are seated upon arrival without having to wait for an available table (either the one to which their reservation was matched, for locked reservations, or any of the tables, for pooled reservations). By definition, then, higher levels of customer service require that a smaller proportion of parties experience a wait. When reservations are locked to specific tables, delivering a higher level of customer service demands a larger time buffer (i.e., a longer table turn time), to ensure that the table will be ready when a party arrives, a procedure that, as reported previously, is used in close to half the restaurants we surveyed. Maintaining a time buffer also allows restaurants to avoid having to ask parties whose dinner is running long to leave or to move to a bar area, practices used by more than half of our survey respondents. Note, though, that with a higher customer service level the table turn time will be longer, even though the actual mean dining duration remains unchanged: it is simply the inherent variability in the dining time that forces a pre-set longer table turn time so that the required proportion of tables are available when customers arrive. In this case, we expect pooling to offer a greater advantage, since pooling allows the variation in dining durations to be buffered by the number of tables in the pool, rather than by each table on its own:

Hypothesis 2a: Pooling reservations will yield a reduced table turn time more frequently under higher levels of customer service.

Smaller restaurants by definition have fewer tables with which to buffer the variation in customer dining times. As such, we expect pooling to reduce table turns less frequently in small restaurants. However, we expect pooling reservations to reduce table turn times more frequently in larger restaurants, similar to how greater parts commonality in manufacturing yields greater 
reductions in safety stock (Collier 1982). The rationale is that bigger pools (i.e., a larger number of tables) offer more opportunity to balance dining duration/arrival time variability. Hence:

Hypothesis $2 \mathrm{~b}$ : Pooling reservations will yield a reduced table turn time more frequently in larger restaurants.

With locked reservations, maintaining a customer service level requires that an increase in the variation in dining duration be covered by a lengthened table turn time (i.e., by increasing the time buffer). Pooling reservations should offer a better hedge against the increased variation in dining duration and should allow the customer service level to be delivered with a reduced table turn time. This result would be consistent with Thompson's (1999) finding that crosstraining benefits increase with greater inaccuracy in forecast errors. Hence:

Hypothesis 2c: Pooling reservations will yield a reduced table turn time more frequently when there is greater variability in dining duration.

\section{Study Designs}

Simulation Factors in Study 1. To investigate the effect of reservation pooling versus locking, we built a simulation model of restaurant-reservations flow. Study 1 had six factors (see Table 3): customer service level (four levels); restaurant size (five levels); mean dining duration (four levels); standard deviation of dining time (four levels); mean party arrival time relative to the reservation time (three levels); and variation in party arrival time (two levels).

\section{[Table 3 here]}

The customer service levels we used were serving 90\%, 95\%, 99\% and 99.9\% of parties without a wait. We included this factor to test hypothesis $2 \mathrm{a}$ and our expectation that pooling will yield faster table turns more often with higher levels of customer service. Though this factor is under control of a restaurant's management, in reality it will be set based on what is appropriate given the restaurant's locality and the preferences of the target market.

We simulated restaurants comprised of 5, 10, 20,50 and 100 tables to allow us to test hypothesis $2 \mathrm{~b}$, that pooling will perform better in larger restaurants. While the number of tables is under management's control prior to the restaurant's construction, this can be considered an environmental factor outside management control for most operating restaurants. We assumed that all tables had four seats (simulation study 2 relaxes this assumption), though this does not require that all parties had four people. Although the results for reservation locking are generalizable to parties larger than four people (if one presumes that tables can be combined to seat larger parties), our simulation did not allow for combining tables. We view this limitation as relatively unimportant given that restaurants perform better with a mix of dedicated table sizes that matches the customer mix, than by having tables that can be combined (Thompson 2002).

Although not related to our hypotheses, we used four levels for the mean dining duration: 45, 50, 55, and 60 minutes. These times are within the range reported in the literature (Bell and Pliner 2003, Kimes and Robson 2004, Kimes and Thompson 2005). We expect to see differences in the effect of reservation pooling across different mean dining durations, though the effects are hard to predict because with locked reservations, increased dining durations will only sometimes require longer table turn times to maintain the customer service level.

The four levels of variation in dining duration were standard deviations of 5,10,15 and 20 minutes, a range consistent with that reported in the literature (Bell and Pliner 2003; Kimes and Robson 2004). We included this factor, which is largely outside management control, to test 
hypothesis $2 \mathrm{c}$, that pooling reservations will allow for more reductions in table turn time under conditions of greater variation in dining times.

We included two other environmental factors to mimic variability related to real-world restaurants. First, we considered that restaurant patrons may not arrive at the time for which their table is reserved. We used three levels of this factor, the first where parties arrive five minutes early, on average; the second where parties arrive on time, on average; and the third where parties arrive five minutes late, on average. This factor is outside management control, but will depend, we assume, on the restaurant's location and the behavioral characteristics of customers.

The final simulation factor, which is also outside management control, is the amount of variation in parties' arrival times. For example, while customer parties may arrive on time on average, some will arrive early and some will arrive late. The two levels we used for this factor were standard deviations of two and four minutes in the arrival times.

Simulation Factors in Study 2. We conducted study 2 to investigate the effect of relaxing study 1 's assumption of all tables having four seats, and instead assumed that the restaurant would contain equal numbers of tables with two, four, six, eight, and ten seats. We also assumed that pooling would occur only within same-sized tables. Study 2 used the same simulation model of restaurant-reservations flow as used in study 1 and some of the same simulation factors, including the four levels of customer service, four of the five restaurant size levels, three of the four levels of mean dining duration, the three levels of mean arrival time of a party measured relative to the reservation time, and the two levels of variation in parties' arrival times. We dropped the 5-table restaurant used in study 1, since this would have resulted in only a single table of each size, which would not allow pooling to occur. In its place we added a level of 500 tables. We also dropped the 45-minute mean dining time and added a 65-minute mean dining time to reflect the finding that larger parties typically take longer to dine (Bell and Pliner 2003, Kimes and Robson 2004, Kimes and Thompson 2005). To capture this characteristic of longer dining durations for larger parties and the four levels for mean dining duration, we lengthened the mean times for each table size (see Table 3 ).

Instead of using a set standard deviation in dining time as in study 1, study 2 used three levels for the coefficient of variation in dining duration. We applied the coefficient of variation to the dining times of each table size, thus permitting the relative variation to remain constant across party sizes. The specific levels - coefficients of variation of $0.100,0.175$, and 0.250 were selected to correspond to the level of variation used in study 1, which itself was based on what has been reported in the literature (Bell and Pliner 2003, Kimes and Robson 2004).

Simulation Assumptions. In conducting the simulation studies, we had nine assumptions, eight of which were common to both studies. First, as noted earlier we assumed in study 1 that every table had four seats, though we relaxed this assumption in study 2 . Second, we assumed log normal dining durations, consistent with the literature (Thompson 2002). Third, we assumed that a party would be seated upon arrival, if a table was available, even if the party arrived earlier than the reservation specified. Fourth, we assumed that the dining duration was measured from the time at which a customer was seated, not the time at which the reservation was scheduled. Fifth, we assumed that the restaurant operated with three, largely independent seatings per meal period. Any overlap in parties in the different seatings would occur either because a party in an earlier seating took a long time to complete their meal, or a party in a later seating arrived early. Sixth, we assumed that the seating times would vary in increments of 15 minutes. This meant that seatings would commence on the hour, 15 minutes past the hour, half-past the hour, and 45 minutes past the hour. We made this assumption because 15-minute periods are the norm in the widely used restaurant reservation portal OpenTable.com. Seventh, we assumed that all tables would be full for each seating. We made this assumption to ensure that we were not biasing the 
studies in favor of pooling reservations (if some tables were empty, pooling would have an additional advantage over locked reservations, since pooling always matches a party to the first available table). Eighth, we assumed that all parties arrived; in other words, there were no noshow parties and no overbooking. Although our survey revealed that $10 \%$ of reservations are noshows, restaurants can take actions to reduce reneging on reservations, including requiring credit card deposits and calling the dining party to reconfirm the reservation. Furthermore, when reservations are locked, there are no tables to which overbooked reservations can be matched. Our assumption disallowing overbooking ensures that any positive effects of pooling will be conservative, since benefits of pooling will be even bigger should overbooking be allowed. Finally, we simulated 1,000 days for each reservation policy, using the same information on customer party arrivals and service durations in both policies to reduce extraneous variance in our results.

Simulation Methodology. The process we used in the simulations was as follows. First, we selected a particular combination of factor levels. Next, using the reservation locking scenario, we searched for the shortest table turn time that met the appropriate target level of customer service. To do this, we started with a 60-minute seating time and increased it in increments of 15 minutes until the customer service level was met. In measuring the service level, we only considered the second and third seatings, since a table would always be available for the first seating. Having established the table turn time for locked reservations, we then examined pooled reservations. Starting with the table turn time we found with the locked reservations, we decreased the time in increments of 15 minutes until the customer service level was no longer met. The table turn time for pooled reservations was the shortest seating interval that still delivered the customer service level.

\section{Results}

Our first hypothesis was that pooling reservations would allow faster table turns than would locking reservations to tables. Of the 1,920 simulated scenarios in study 1 , pooling reduced the table turn time in 370 , or in $19.3 \%$ of the cases (mean table turn time for locked reservations $=110.0$ minutes, mean table turn for pooled reservations $=107.1$ minutes, $\mathrm{t}(1920)=$ $21.40, \mathrm{p}=0.000)$. Pooling also reduced the table turn time in 163 of the 1,440 scenarios $(11.3 \%)$ in study 2 (mean table turn time for locked reservations $=129.6$ minutes, mean table turn for pooled reservations $=127.9$ minutes, $t(1,440)=13.55, \mathrm{p}=0.000)$. In all instances across both studies where pooling reduced the table turn time, the reduction was 15 minutes.

Table 4 summarizes the conditions under which pooling reduced table turn times. As an example of how to read the table, consider a table turn time of 90 minutes. With locked reservations, this table turn time was necessary to deliver the customer service level in 552 of the 1,920 scenarios in study 1 and in 272 of the 1,440 scenarios in study 2 . Of those 552 (272) scenarios in study 1 (study 2), pooling reservations enabled the table turn time to be reduced by 15 minutes (to 60 minutes) in 79 (16), or $14.3 \%$ (5.9\%) of the cases. Enhanced service efficiency was most evident under a 210-minute table turn time in study 1 and a 240 minute table turn time in study two, with table turn times lowered in more than $70 \%$ of the scenarios in both studies.

\section{[Table 4 here]}

In the tables that follow, we first show how pooling reduced table turn times across the levels of our experimental factors. We then provide statistical tests for our second hypothesis. Table 5 reports the number of scenarios in which pooling reservations reduced the table turn time 
across the four levels of customer service we examined. In study 1 (study 2) pooling reservations reduced table turn times in $10 \%(9 \%)$ of the scenarios with the lowest customer service level, increasing to more than $33 \%(18 \%)$ of the scenarios at the highest customer service level we tested, in support of hypothesis 2 a.

\section{[Table 5 here]}

Table 6 identifies the number of scenarios in each study, for each restaurant size (based on numbers of tables), for which pooling reduced table turn times. The results support hypothesis $2 \mathrm{~b}$, since the benefit of pooling increased with restaurant size. Diminishing returns were observed, however. For example, doubling the number of tables from 5 to 10 in study 1 resulted in an increase of $74 \%$ in the number of scenarios in which pooling reservations reduced table turn times, but a comparable doubling of the number of tables from 50 to 100 only resulted in an increase of $11 \%$ in the number of scenarios in which pooling reduced table turn times.

\section{[Table 6 here]}

Tables 7 and 8 present the results across the levels of variability in dining duration for studies 1 and 2. Pooling reservations had a fairly stable effect across increasing dining-duration standard deviations (study 1) and coefficients of variation (study 2).

\section{[Tables $7 \& 8$ here]}

Tables 9 through 11 present results for the effectiveness of reservation pooling across the levels of other factors. As reported in Table 9, pooling reservations reduced table turn times more frequently in study 1 with 50- and 55-minute than with 45- or 60-minute mean dining durations, and more frequently in study 2 with 55- and 60-minute than with 50- or 65-minute dining durations. Table 10 shows that reservation pooling most often reduced table turn times when customer parties arrived five minutes late for their reservation on average, and reduced table turns the least often when customer parties arrived five minutes early, on average. The variation in customer party arrival times had a large effect on how often reservation pooling reduced table turn times (see Table 11). A four-minute standard deviation in customer party arrival times increased the number of scenarios in which pooling reduced table turn times more than threefold, compared to a two-minute standard deviation in customer party arrival times.

\section{[Tables 9, 10, \& 11 here]}

To summarize our results, we observed that pooling reservations allowed a 15-minute reduction in table turn times in more than $19 \%$ of the simulation scenarios in study 1 and in more than $11 \%$ of the scenarios in study 2 . Pooling had more consistent advantages in those cases with higher customer service levels, in larger restaurants, where patrons are late on average, and where there are larger variations in arrival times. Pooling was better, on average, across the factor levels for dining duration and dining duration variability, though the levels themselves of these factors had mixed effects. The faster table turns under pooled reservations means that the service efficiency increases with pooling, which can lead to higher revenues.

To further explore the relationship between the factors examined in the studies and the benefits of pooling, and to statistically test our second hypothesis, we performed a logistic regression (Pezzullo 2007), as reported in Table 12. The independent variables were the six 
factors in each study, with the levels of each factor coded as increasing integers (i.e., 1, 2, 3,...). The dependent variable was assigned a value of one if pooling reduced the table turn time, and zero otherwise. Results for both studies support hypotheses $2 \mathrm{a}$ - that higher customer service levels increase the likelihood that pooling reduces the table turn time. In hypothesis $2 \mathrm{~b}$ we proposed that pooling reservations would yield more frequent reductions in table turn times in larger restaurants. This hypothesis was supported in study 2, but not in study 1 . Finally, hypothesis $2 \mathrm{c}$ stated that pooling reservationswould more frequently yield reductions in table turn times when there is greater variability in dining duration. Support for this was modest in study $1(\mathrm{p}<0.05)$ and weak $(\mathrm{p}<0.1)$ in study 2 . Overall, we conclude that our hypotheses were supported, although only the service level effect was strongly supported across both studies.

\section{[Table 12 here]}

\section{Limitations}

As with any research, there are limitations to our simulation studies. First, we allowed no over-booking and we assumed that there were no no-show parties. We reiterate that we did not include overbooking and no-shows because that would have given pooling an unfair advantage over locking reservations. Moroever, managers use a variety of actions to reduce the frequency of no-shows, as revealed in by the survey results. However, because overbooking is problematic with reservations locked to specific tables, relaxing these assumptions are left to future research.

We assumed three seatings per meal period, scheduled consecutively. Staggered dining times are more typical in full-service restaurants, since staggered times balance the demands on the kitchen and waitstaff. With staggered reservations, pooling will have fewer tables to pool at any particular reservation time. Mitigating this, however, would be the ability to block tables for unequal time durations. In both simulation studies, all tables had the same turn time. However, with rolling reservations one could implement a strategy where some tables were assumed to turn more quickly, and some more slowly. We expect that this would be a fruitful area of investigation.

Finally, there certainly can be situations where a restaurant owner wants to match reservations to specific parties, such as for handling special tables and guest preferences for specific tables. Nonetheless, our results show that by pooling any tables that can be pooled, restaurants gain the ability to reduce the table turn time and improve service efficiency.

\section{DISCUSSION}

Our simulation showed that pooling restaurant reservations generally is a more efficient service process than locking reservations to specific tables. However, pooling reservations does not affect table turn times more frequently than it does: pooling reduced table turn times by 15 minutes only about $15 \%$ of the time across our simulations. Still, there are two considerations. First, pooling never lengthens table turn times, so at worst it yields the same efficiency as does locking reservations. Second, pooling reservations is more effective in some situations: higher customer service levels, larger restaurants, where patrons are late on average, and where there are larger variations in arrival times. Consider scenarios from study 2 with a customer service level of $99.9 \%$, a 500-table restaurant, parties five minutes late on average, and a four-minute standard deviation in arrival time. Pooling reservations reduced the table turn time in 10 of the 12 scenarios like this. Other than the customer service level, these factors are largely outside management control; that is, a manager is not going to change the size of a restaurant simply to 
gain a pooling benefit. The implication of these findings is that there are definitely circumstances when restaurants should be pooling reservations.

Locking creates problems for managers: they need to ensure that parties show up, and that parties finish in time for the next reservation. To avoid tables being occupied when a party arrives for its reservation, our survey showed that managers attempt to control dining processes by informing patrons of table time limits or moving them to an overflow area, or by asking the arriving party to wait for their table. About half of our survey respondents also build in buffer time into the reservation, which essentially reduces the capacity of the restaurant. Pooling offers an opportunity to recapture that lost time, without the risk of dissatisfying customers that comes with moving parties, asking them to depart, or forcing parties with reservations to wait. As noted earlier, pooling reservations also makes it easier to manage the logistics of overbooking.

Given the limitations of locking reservations, it is reasonable to question why we find that $80 \%$ of restaurants lock reservations to tables either at the time the reservation is made or before the meal period begins. We believe there are several reasons for this. First, pooling requires a more complex tracking process, particularly with staggered dining times, to ensure that overbooking does not occur. For manual reservation processes, locking reservations can reduce the possibility of errors, permit a better view of table availability, enable an easier arrangement of the table mix prior to guest arrival, and facilitate accommodation of guests with table preferences. Second, we saw that not all vendors of table-management applications support pooling reservations. A third reason, we believe, is that this research is the first to actually attempt to quantify the benefits of pooling restaurant reservations.

There are implications that arise from the reasons managers lock reservations. First, restaurateurs that currently lock reservations to tables should examine whether pooling reservations would work better in their restaurants. The practice of locking reservations is perceived to reduce complexity and uncertainty; however, locking reservations creates problematic outcomes related to processes (e.g., under-utilized tables due to pre-set longer dining durations and no-shows) and customer experience failures (e.g., moving waiting and/or dining customers to overflow areas and the inability to efficiently accommodate walk-in customers). Second, restaurants that use commercial systems should consider only systems that offer both locking and pooling options, and that make it easy to handle the real-time management of walkin parties and parties with reservations, should a restaurant choose to pool reservations. Third, restaurants that use manual systems should organize their information in a way that allows pooling, yet retains the perceived ease-of-use advantages of locking reservations.

We see at least six extensions to our work. First, the benefit of pooling had a complex relationship with respect to dining duration and so warrants further study. Second, pooling reservations becomes more complicated when reservations are taken on a rolling basis. For example, we foresee advantages coming from tables in a pool being blocked for different lengths of time. Third, pooling across table sizes may have advantages under some circumstances, instead of assuming that pooling occurs only for same-sized tables, as we have done here. Fourth, as we noted earlier, incorporating no-shows and overbooking as factors would increase the realism of any study focusing solely on pooling. Overbooking has been studied extensively in the lodging and airline settings (Chiang, Chen, and Xu 2007), but as yet restaurant overbooking has received little attention. Studies of restaurant overbooking may be particularly useful given that consumers respond more strongly to negative experiences from overbooking than they do to positive experiences such as upgrading (von Wangenheim and Bayón 2007). Fifth, simple, manual systems that allow managers to pool reservations should be developed, given that twothirds of our survey respondents use manual reservations and table management systems. Finally, we studied reservation pooling in a restaurant context, but there are other services (e.g., medical 
practices) that suffer from waits, overbooking, and inefficient asset utilization, and for which the pooling approach to managing customer flow may yield service efficiencies.

Our study has confirmed the benefit of pooling restaurant reservations in comparison to locking reservations to specific tables. This is yet another instance when a form of resource pooling has been shown to yield improved performance. The key takeaway is that pooling reservations does not perform worse than locking reservations and often makes a significant difference in table turn times. Pooling reservations increases service efficiency and allows more customers to be served; thus, it behooves the restaurant industry - and possibly similar capacityconstrained services - to adopt the practice.

\section{REFERENCES}

Bell, Rick and Patricia L. Pliner (2003), "Time To Eat: The Relationship Between the Number of People Eating and Meal Duration In Three Lunch Settings," Appetite, 41, 215-218.

Bertsimas, Dimitras and Romy Shioda (2003), "Restaurant Revenue Management," Operations Research, 51 (3), 472-486.

Cayirli, Tugba and Emre Veral (2003), "Outpatient Scheduling In Health Care: A Review of Literature," Production and Operations Management, 12 (4), 519-549.

Chiang, Wen-Chyuan, Jason C. H. Chen and Xiaojing Xu (2007), "An Overview of Research on Revenue Management: Current Issues and Future Research," International Journal of Revenue Management, 1 (1), 97-127.

Collier, David (1982), "Aggregate Safety Stock Levels and Component Part Commonality," Management Science, 28 (November), 1296-1303.

Kimes, Sheryl E. and Richard B. Chase (1998), "The Strategic Levers of Yield Management," Journal of Service Research, 1 (2), 156-66.

Kimes, Sheryl E. and Stephani K. A. Robson (2004), "The Impact of Restaurant Table Characteristics on Meal Duration and Spending," Cornell Hotel and Restaurant Administration Quarterly, 45 (4), 333-346.

------ and Gary M. Thompson (2004), "Restaurant Revenue Management at Chevys: Determining the Best Table Mix," Decision Sciences, 35 (3), 371-392.

------ and ------ (2005), “An Evaluation of Heuristic Methods for Determining the Best Table Mix in Full-Service Restaurants," Journal of Operations Management, 23 (6), 599-617. ------, Jochen Wirtz, and Breffni M. Noone (2002), “How Long Should Dinner Take? Measuring Expected Meal Duration for Restaurant Revenue Management," Journal of Revenue and Pricing Management, 1 (3), 220-233.

Parasuraman, A (2007), "JSR Welcomes Modeling Papers and Manuscripts from Multiple Disciplines," Journal of Service Research, 9 (4), 291-292.

Pasin, Federico, Marie-Hélène Jobin, and Jean-François Cordeau (2002), “An Application of Simulation to Analyse Resource Sharing among Health-care Organisations,"

International Journal of Operations and Production Management, 22 (4), 381-393.

Pezzullo, John C. (2007), Logistic Regression v. 05.07.20 (http://statpages.org/logistic.html).

Pullman, Madeleine E. and Gary M. Thompson (2003), "Strategies for Integrating Capacity with Demand in Service Networks," Journal of Service Research, 5 (3), 169-183.

Sheu, Chwen and John G. Wacker (1997), "The Effects of Purchased Parts Commonality on Manufacturing Lead Time," International Journal of Operations and Production Management, 17 (August), 725-745.

Thompson, Gary M. (1999), "Labor Scheduling Part 4: Controlling Workforce Schedules in Real Time," Cornell Hotel and Restaurant Administration Quarterly, 40 (June), 85-96. 
------ (2002), “Optimizing a Restaurant's Seating Capacity: Use Dedicated or Combinable Tables?" Cornell Hotel and Restaurant Administration Quarterly, 43 (August), 48-57. ------ and Rohit Verma (2003), "Computer Simulation in Hospitality Teaching, Practice and Research," Cornell Hotel and Restaurant Administration Quarterly, 44 (2), 85-93.

Vanden Bosch, Peter M. and Dennis C. Dietz (2001), "Scheduling and Sequencing Arrivals to an Appointment System," Journal of Service Research, 4 (1), 15-25.

von Wangenheim, Florian and Tomás Bayón (2007), "Behavioral Consequences of Overbooking Service Capacity," Journal of Marketing, 71 (4), 36-47.

Wilson, Robert H. (2007), "Internet Hotel Reservations: The 'Terms and Conditions' Trap," Cornell Hotel and Restaurant Administration Quarterly, 48 (4), 361-69. 


\section{FIGURE 1}

Alternative Forms of Handling Restaurant Reservations

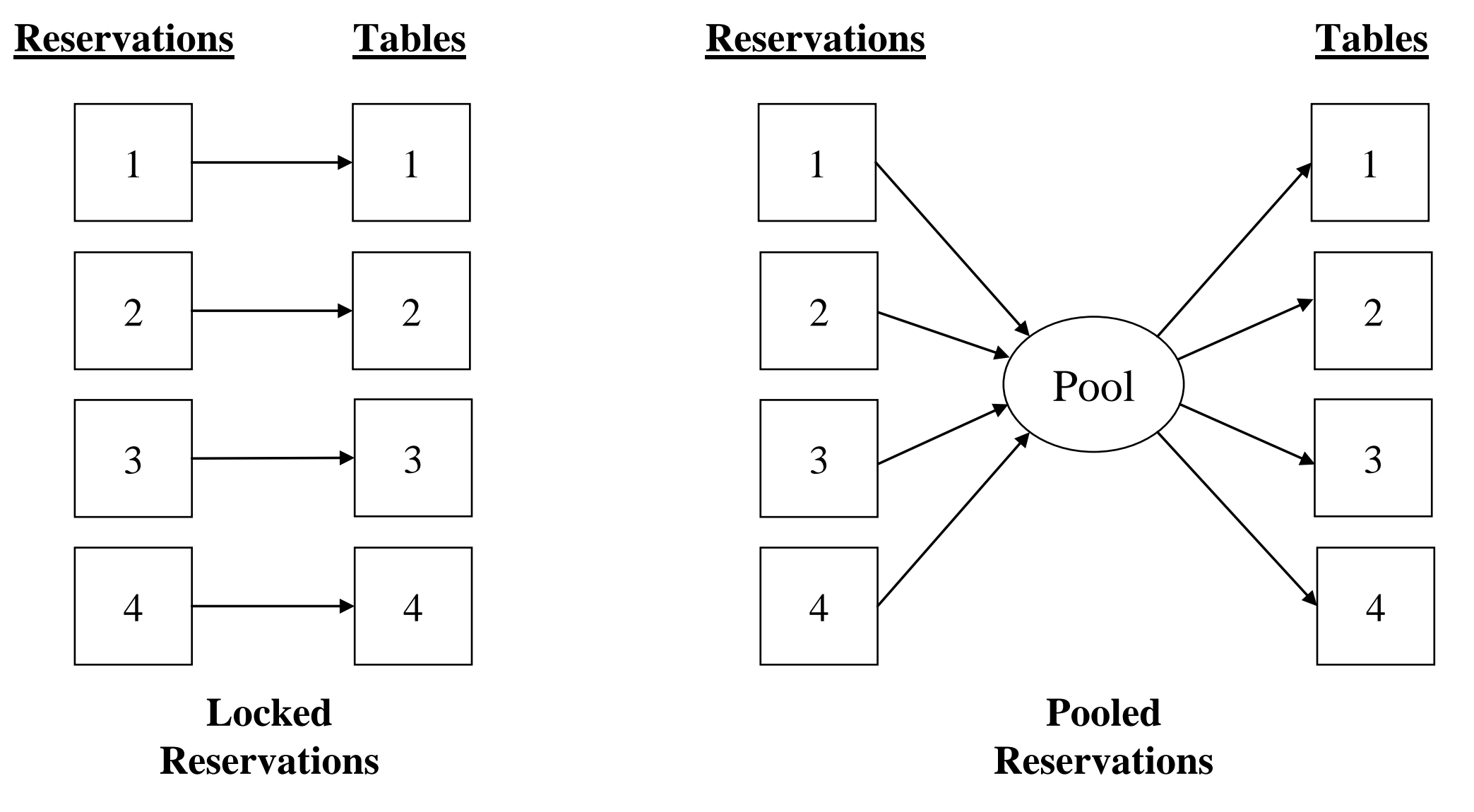




\section{TABLE 1}

\section{Reservation Handling in Commercially Available Restaurant Reservation Systems}

\begin{tabular}{llc}
\hline \multicolumn{1}{c}{ Vendor (Website) } & \multicolumn{1}{c}{ Product } & Locked or Pooled \\
\hline 1TouchSoftware Solutions (1touchsoftware.com) & 1Touch eRMS & Either \\
Advanced Hospitality Systems (advancedhospitality.com) & NTN RSViP & Locked** \\
Ameranth Wireless (amaranth.com) & HostAlert & NR* \\
Analytical Systems (analyticalsystems.com.au) & ResPAK & Either \\
Avenista (www.avenista.com) & Avenista Table Reservation Software & NR* \\
CommerceTech (***) & DiningPlus & Locked \\
Efficient Frontiers (reserveinteractive.com) & Reserve Interactive & Pooled \\
GuestBridge (guestbridge.com) & GuestBridge reserve & NR* \\
iMagic (imagicrestaurantsoftware.com) & iMagic Restaurant Reservation & Locked \\
OpenTable (opentable.com) & OpenTable & SilverWare \\
SilverWare POS (silverwarepos.com) & Either & NR*
\end{tabular}

$* \mathrm{NR}=$ no response from vendor.

**Pooled in advance, but under control of host/hostess two hours prior to party arrival, when locking occurs.

****Does not have a dedicated website. Software available from third-party sites. 
TABLE 2

\section{Reasons Why Restaurants Lock Reservations to Specific Tables}

Rationale for the Practice of Locking Reservations

Simplifies reservations and table management

Enables easier physical arrangement of the table mix before guests with reservations arrive

Some guests request specific tables

Permits a better view of table availability

Reduces the possibility of reservation and seating errors

Easier for staff to understand

It is the only option available in our table management system

Other

\section{Percent*}

50.4

42.6

41.5

39.2

36.4

25.2

2.2

2.2

* "Percent" is the percentage of respondents out of 357 who selected the respective rationale options in response to the question, "If you assign (or lock) reservations to specific tables, what are the main reasons you use this practice (check all that apply)." 


\section{TABLE 3}

\section{Factors in Simulation Studies}

\begin{tabular}{|c|c|c|c|}
\hline Factor & $\begin{array}{c}\# \\
\text { Levels }\end{array}$ & Levels & $\begin{array}{l}\text { Used in } \\
\text { Study }\end{array}$ \\
\hline Customer service level & 4 & Serving $90 \%, 95 \%, 99 \%$ and $99.9 \%$ of customer parties without a wait & 1,2 \\
\hline Restaurant size & 5 & $\begin{array}{l}5^{*}, 10,20,50,100 \text { and } 500 * * \text { tables (all of } 4 \text { seats* or equal numbers of } \\
2-, 4-, 6-, 8 \text { - and } 10 \text {-seat tables**) }\end{array}$ & 1,2 \\
\hline Mean dining duration & 4 & $45,50,55$, and 60 minutes & 1 \\
\hline Mean dining duration & 4 & $\begin{array}{l}50 \text { minutes }(45.0,47.5,50.0,52.5,55.0 \text { minutes for tables of } 2,4, \ldots, 10 \\
\text { seats); } 55 \text { minutes }(45.0,50.0,55.0,60.0,65.0 \text { minutes for tables of } 2 \text {, } \\
4, \ldots, 10 \text { seats }) ; 60 \text { minutes }(45.0,52.5,60.0,67.5,75.0 \text { minutes for } \\
\text { tables of } 2,4, \ldots, 10 \text { seats); and } 65 \text { minutes }(45.0,55.0,65.0,75.0,85.0 \\
\text { minutes for tables of } 2,4, \ldots, 10 \text { seats })\end{array}$ & 2 \\
\hline Standard deviation of dining time & 4 & Standard deviations of $5,10,15$ and 20 minutes & 1 \\
\hline Coefficient of variation in dining duration & 3 & $0.100,0.175,0.250$ & 2 \\
\hline $\begin{array}{l}\text { Mean arrival time of a party, relative to the } \\
\text { reservation time }\end{array}$ & 3 & 5 minutes early, on-time, 5 minutes late & 1,2 \\
\hline Variation in the party arrival time & 2 & Standard deviations of two and four minutes in the arrival times & 1,2 \\
\hline
\end{tabular}

*Study 1 only.

**Study 2 only. 
TABLE 4

Summary of Reduction of Table Turn Time Yielded by Pooling Reservations

\begin{tabular}{|c|c|c|c|c|}
\hline \multirow{4}{*}{$\begin{array}{l}\text { Table } \\
\text { Turn } \\
\text { Time }\end{array}$} & \multicolumn{2}{|c|}{ Simulation Study 1} & \multicolumn{2}{|c|}{ Simulation Study 2} \\
\hline & \# Scenarios & \# (\%) Scenarios where & \# Scenarios & \# (\%) Scenarios where \\
\hline & with Locked & Pooling Reservations reduced & with Locked & Pooling Reservations \\
\hline & Reservations & the Table Turn Time & Reservations & reduced the Table Turn Time \\
\hline 60 & 25 & $0(0.0 \%)$ & 0 & $0(\mathrm{~N} / \mathrm{A})$ \\
\hline 75 & 337 & $14(4.2 \%)$ & 76 & $0(0 \%)$ \\
\hline 90 & 552 & $79(14.3 \%)$ & 272 & $16(5.9 \%)$ \\
\hline 105 & 372 & $77(20.7 \%)$ & 292 & $44(15.1 \%)$ \\
\hline 120 & 188 & $17(9.0 \%)$ & 235 & $32(13.6 \%)$ \\
\hline 135 & 129 & $61(47.3 \%)$ & 175 & $31(17.7 \%)$ \\
\hline 150 & 77 & $34(44.2 \%)$ & 90 & $10(11.1 \%)$ \\
\hline 165 & 120 & $45(37.5 \%)$ & 60 & $0(0 \%)$ \\
\hline 180 & 0 & $0(\mathrm{~N} / \mathrm{A})$ & 111 & $0(0 \%)$ \\
\hline 195 & 59 & $0(0.0 \%)$ & 10 & $5(50 \%)$ \\
\hline 210 & 61 & $43(70.5 \%)$ & 29 & $7(24.1 \%)$ \\
\hline 225 & 0 & $0(\mathrm{~N} / \mathrm{A})$ & 8 & $0(0 \%)$ \\
\hline 240 & 0 & 0 (N/A) & 22 & $16(72.7 \%)$ \\
\hline 255 & 0 & $0(\mathrm{~N} / \mathrm{A})$ & 50 & $0(0 \%)$ \\
\hline 270 & 0 & $0(\mathrm{~N} / \mathrm{A})$ & 10 & $2(20 \%)$ \\
\hline Total & 1,920 & $370(19.3 \%)$ & 1,440 & $163(11.3 \%)$ \\
\hline
\end{tabular}


TABLE 5

Table Turn Time Reductions by Customer Service Level

\begin{tabular}{ccc}
\hline $\begin{array}{c}\text { Customer Service } \\
\text { Level }\end{array}$ & $\begin{array}{c}\text { Simulation Study 1 (480 } \\
\text { observations per level) }\end{array}$ & $\begin{array}{c}\text { Simulation Study 2 (360 } \\
\text { observations per level) }\end{array}$ \\
\hline $90 \%$ & $48(10.0 \%)$ & $32(8.9 \%)$ \\
$95 \%$ & $55(11.5 \%)$ & $43(11.9 \%)$ \\
$99 \%$ & $108(22.5 \%)$ & $22(6.1 \%)$ \\
$99.9 \%$ & $159(33.1 \%)$ & $66(18.3 \%)$ \\
\hline
\end{tabular}

\# (\%) of scenarios where pooling reservations reduced the table turn time

TABLE 6

Table Turn Time Reductions by Restaurant Size

\begin{tabular}{ccc}
\hline $\begin{array}{c}\text { Number of } \\
\text { Tables }\end{array}$ & $\begin{array}{c}\text { Simulation Study 1 (384 } \\
\text { observations per level) }\end{array}$ & $\begin{array}{c}\text { Simulation Study 2 (288 } \\
\text { observations per level) }\end{array}$ \\
\hline 5 & $39(10.2 \%)$ & N/A \\
10 & $68(17.7 \%)$ & $9(3.1 \%)$ \\
20 & $75(19.5 \%)$ & $20(6.9 \%)$ \\
50 & $89(23.2 \%)$ & $35(12.2 \%)$ \\
100 & $99(25.8 \%)$ & $38(13.2 \%)$ \\
500 & N/A & $61(21.2 \%)$ \\
\hline
\end{tabular}

\# (\%) of scenarios where pooling reservations reduced the table turn time 
TABLE 7

Table Turn Time Reductions in Simulation Study 1 by Dining Duration Standard Deviation

\begin{tabular}{cc}
\hline $\begin{array}{c}\text { Standard Devation of } \\
\text { Dining Duration (minutes) }\end{array}$ & $\begin{array}{c}\text { \# (\%) of Scenarios (of 480) where Pooling } \\
\text { Reservations Reduced the Table Turn Time }\end{array}$ \\
\hline 10 & $79(16.5 \%)$ \\
15 & $103(21.5 \%)$ \\
20 & $89(18.5 \%)$ \\
25 & $99(20.6 \%)$ \\
\hline
\end{tabular}

TABLE 8

Table Turn Time Reductions in Simulation Study 2 by Dining Duration Coefficient of

Variation

\begin{tabular}{cc}
\hline $\begin{array}{c}\text { Coefficient of Variation of } \\
\text { Dining Duration }\end{array}$ & $\begin{array}{c}\text { \# (\%) of Scenarios (of 480) where Pooling } \\
\text { Reservations Reduced the Table Turn Time }\end{array}$ \\
\hline 0.100 & $57(11.9 \%)$ \\
0.175 & $64(13.3 \%)$ \\
0.250 & $42(8.8 \%)$ \\
\hline
\end{tabular}


TABLE 9

Table Turn Time Reductions by Mean Dining Duration

\begin{tabular}{ccc}
\hline $\begin{array}{c}\text { Mean Dining } \\
\text { Duration (minutes) }\end{array}$ & $\begin{array}{c}\text { Simulation Study 1 (480 } \\
\text { observations per level) }\end{array}$ & $\begin{array}{c}\text { Simulation Study 2 (360 } \\
\text { observations per level) }\end{array}$ \\
\hline 45 & $77(16.0 \%)$ & N/A \\
50 & $123(25.6 \%)$ & $41(11.4 \%)$ \\
55 & $104(21.7 \%)$ & $62(17.2 \%)$ \\
60 & $66(13.8 \%)$ & $49(13.6 \%)$ \\
65 & N/A & $11(3.1 \%)$ \\
\hline
\end{tabular}

\# (\%) of scenarios where pooling reservations reduced the table turn time

TABLE 10

Table Turn Time Reductions by Mean Relative Arrival Time

\begin{tabular}{ccc}
\hline $\begin{array}{c}\text { Mean Relative Arrival } \\
\text { Time (minutes) }\end{array}$ & $\begin{array}{c}\text { Simulation Study 1 (640 } \\
\text { observations per level) }\end{array}$ & $\begin{array}{c}\text { Simulation Study 2 (480 } \\
\text { observations per level) }\end{array}$ \\
\hline-5 & $42(6.6 \%)$ & $12(2.5 \%)$ \\
0 & $138(21.6 \%)$ & $56(11.7 \%)$ \\
5 & $190(29.7 \%)$ & $95(19.8 \%)$ \\
\hline
\end{tabular}

\# $(\%)$ of scenarios where pooling reservations reduced the table turn time 
TABLE 11

Table Turn Time Reductions by Standard Deviation of Relative Arrival Times

\begin{tabular}{ccc}
\hline $\begin{array}{c}\text { Standard Deviation of Relative } \\
\text { Arrival Time (minutes) }\end{array}$ & $\begin{array}{c}\text { Simulation Study 1 (960 } \\
\text { observations per level) }\end{array}$ & $\begin{array}{c}\text { Simulation Study 2 (720 } \\
\text { observations per level) }\end{array}$ \\
\hline 2 & $89(9.3 \%)$ & $46(6.4 \%)$ \\
4 & $281(29.3 \%)$ & $117(16.3 \%)$ \\
\hline
\end{tabular}

\# (\%) of scenarios where pooling reservations reduced the table turn time 
TABLE 12

Logistic Regression Results

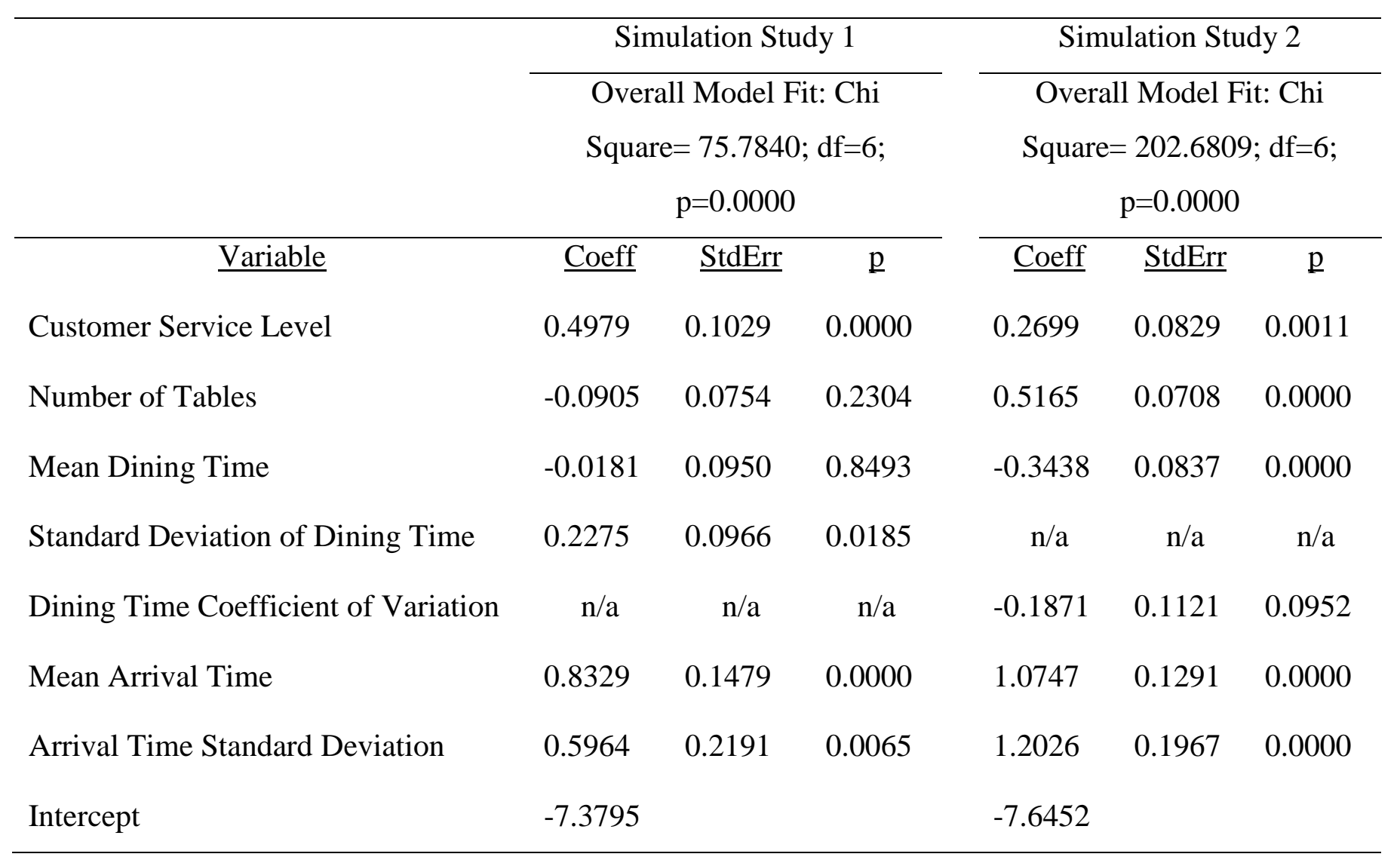


GARY M. THOMPSON is Professor of Operations Management in the School of Hotel Administration at Cornell University, where he teaches graduate and undergraduate courses in Service Operations Management. He holds a B.Sc. with First Class Honours (University of New Brunswick), an M.B.A. (University of Western Ontario), and a Ph.D. in Operations Management (The Florida State University). His current research focuses on wine cellars, restaurant operations, and conference and course scheduling. He has consulted for several prominent hospitality companies and is the founder and president of Thoughtimus ${ }^{\circledR}$ Inc. In his free time, he enjoys koi watching and fine red wine.

ROBERT J. KWORTNIK, Ph.D., is an assistant professor of services marketing in the School of Hotel Administration at Cornell University. His research focuses on consumer behavior for services, with particular attention to decision making for and the design and management of service experiences. He also specializes in the leisure cruise industry and grounds much of his research in that service context. His work has appeared in the International Journal of Research in Marketing, Psychology \& Marketing, The Journal of Consumer Policy, and the Cornell Hotel \& Restaurant Administration Quarterly. 